\title{
Undergraduate Reactions to Teaching Assistants
}

\section{Robert J. Menges and Jeremy Wilson}

It is estimated that graduate teaching assistants are responsible for one-fourth to one-half of the undergraduate teaching load in American universities (Friedrich, 1979). Although institutions are understandably reluctant to publicize precise statistics, it is clear that graduate teaching assistants are the "professors" in a significant proportion of student-faculty contacts, particularly in courses for freshmen and sophomores.

The topic of preparing graduate students for teaching is approached in the literature in several ways. For example, Williams (1977) discusses the evolution of institutional policies regarding graduate teaching assistants. Training programs have been described and evaluated in journals devoted to teaching (e.g., Staton-Spicer \& Nyquist, 1979; Levinson-Rose \& Menges, 1981). Special materials have been developed for use by teaching assistants (e.g., Change Magazine, 1978).

Normative information about teaching assistants' duties and activities is, however, absent from the literature. In particular, we find no cross-department information about what teaching assistants do in their classes and labs, about students' satisfaction and dissatisfaction with what happens during those meetings, and about students' preferences regarding how meetings should be conducted. 


\section{A Survey}

In order to establish some basic information about teaching assistant instruction, a survey was conducted in a sample of large, multisection, lecture courses at Northwestern University. Supervisory faculty were asked to distribute an additional form (see Appendix A) with the course evaluation form they regularly use at the end of the quarter. Students were assured the survey was a separate study by the University Curriculum and Teaching Committee and would not be published as regular evaluations are. Teaching assistants were not identified by name, but the time and place of the meeting were noted; then data were combined across sections for each teaching assistant.

Usable questionnaires were returned by approximately 1,800 students in 44 different section of 14 courses in the same number of departments (anthropology, art history, biochemistry, biology, economics, geography, geology, history, religion, philosophy, physics, political science, psychology, and slavic languages). Each course had multiple sections except a social science department with only one quiz section and one science department where the number of responses for individual sections was so small that the results were pooled for the department only. With the exception of the latter course, response rates by course ranged from 50 percent to 85 percent.

\section{General Characteristics of Respondents}

Approximately 70 percent of the respondents were either freshman or sophomores. Their school of enrollment closely paralleled enrollments within the University: slightly less than two-thirds were in the College of Arts and Sciences and others were enrolled in one of five undergraduate professional schools. About a third of the respondents had three or fewer teaching assistants at the University, while nearly 30 percent had ten or more. Nearly half ( 46 percent) had been exposed to at least seven teaching assistants.

Ninety percent of respondents claimed to have attended the course section taught by the teaching assistant all or most of the time. Ninety-three percent said the teaching assistant was never absent from a scheduled meeting; only 1 percent indicated two or more absences. In responding to whether the teaching assistant attended the scheduled 
lecture sections of the course, 20 percent of the students reported they did not know, while 71 percent responded al or most of the time.

Students were also asked the extent to which they believed the teaching assistant was responsible for grading; 71 percent answered either largely or totally responsible and only 17 percent answered somewhat or not at all.

In summary, we conclude that respondents are fairly representative of our undergraduates, that they and their teaching assistant attend meetings regularly, that there is good attendance by the teaching assistant at course lectures, and that teaching assistants are perceived has having major responsibility for grading student work. About two-thirds of respondents had concurrent or previous experience with at least four teaching assistants with whom the present teaching assistant could be compared.

\section{Perceived Quality of Teaching}

Five questions evaluated the work of the teaching assistant. Responses were highly positive. Eighty-five percent of all respondents agreed or agreed strongly that the teaching assistant was well prepared for each meeting; 83 percent agreed or agreed strongly that the teaching assistant conveyed a thorough knowledge of the subject; 71 percent agreed or agreed strongly that the teaching assistant was readily available after class or during office hours for questions or consultation; 80 percent agreed or agreed strongly that the teaching assistant showed enthusiasm for the course; finally, 68 percent felt that contact with the teaching assistant enhanced or somewhat enhanced the course.

These items are positively correlated, as one might expect. The lowest correlation between any pair of items is .43 (knowledge and availability) and the highest correlation between any pair is .76 (knowledge and preparation). For further analysis, a composite score was created for each teaching assistant representing the average of the sum of these five evaluative questions across all of his or her students. All items were scored with higher numbers meaning more positive ratings. 
Note the composite scores for courses or for teaching assistants are lower than might be expected from the percent of agreement with individual items. As it happens, teaching assistants in several of the larger courses received relatively high ratings and those in smaller courses received relatively low ratings. Thus, the distribution of composite scores and its mean is depressed, since the composite score does not take account of differential enrollments. The mean rating across all teaching assistants in all courses is 3.1 (standard deviation of .9).

Courses were grouped into disciplinary families for comparison: humanities, social science, and science. The mean rating for humanities is 3.1, for social science 3.0, and for science 2.7. As Figure 1 shows, differences within families of courses are substantial (a range of 1.0 for humanities, .9 for social sciences, and 1.0 for science).

Within particular courses there is also considerable variability. Ratings of the four teaching assistants in one science course, for example, ranged from 1.7 to 3.2 , greater than the difference between any two courses. Figure 2 shows ratings of each teaching assistant in the five social science courses. (Note that most teaching assistants had more than one section and that these are averages across students in all sections of that teaching assistant.) The difference between the highest rated and lowest rated is 1.3 .

We regard these ratings as satisfactory. Nevertheless, it is clear that some courses (and some teaching assistants) are regarded as considerably more effective than others.

\section{How Time is Spent}

Students were asked to estimate the proportion of time spent in various activities: clarifying readings, clarifying lecture material, introducing new material, taking quizzes or exams, grading and discussing quizzes or exams, dealing with assignments, and so on. Space permits reporting data for only one type of activity: classroom talk.

Students were asked to estimate the proportion of time spent in talking by the teaching assistant and the proportion of time spent in talking by students. As might be expected, differences across courses (Figure 3 ) are considerably greater than differences within courses. 
(Figure 4 shows estimates for each social science teaching assistant.) Averaging all student responses, teaching assistant talk was estimated at 54 percent of class time (standard deviation of 24 percent). Estimates ranged across courses from a low of 24 percent to a high of 79 percent.

One humanities course had a range across its teaching assistants of 22 percent, but all other courses were 16 percent or less. The estimates for social science teaching assistants shown in Figure 4 are typical. As with effectiveness ratings, the maximum range was not found in courses with the largest number of sections.

We conclude that there are rather characteristic differences across courses and consistent patterns within courses in terms of the proportion of time spent by teaching assistants and students respectively in classroom talk.

\section{How Time Should be Spent}

In addition to estimating time spent in classroom talk, students were asked to indicate the proportion of time they prefer be devoted to teaching assistant and student talk. (See Figure 3 for all courses and Figure 4 for social science teaching assistants.) Students appear to be generally satisfied with the present situation. The preferred proportion varies from the estimated proportion in the direction of slightly less talk by the teaching assistant and slightly more by the student. If these preferences were reality, rates would become more uniform across courses.

\section{Experience with Other Teaching Assistants}

As noted above, respondents varied in the number of teaching assistants they had at the University. About a third had three or fewer, while nearly 30 percent had ten or more. The students were asked, "How competent have you found them to be in their own special fields?" Twenty-eight percent reported that all were competent, 26 percent that one was not sufficiently competent, 33 percent that two or three were not sufficiently competent, and 13 percent that several were not sufficiently competent. 
This item parallels a question asked each year of a sample of freshmen and seniors concerning their experiences with faculty. In 1980, eight percent of freshmen and 17 percent of seniors responded "several not sufficiently competent" concerning instructors in their own special fields. We conclude that the general experience students have with teaching assistants is about the same or better than that which they had with faculty.

\section{For Further Investigation}

This survey provides normative data from one institution on undergraduate perceptions of teaching assistants. It shows general satisfaction among undergraduates with the quality of teaching assistant instruction and with how teaching assistants allocate time to class activities. But it also shows large differences across courses and across teaching assistants.

Such data are useful for gross comparisons, for identifying areas of need, and, if regularly gathered, for documenting the effects of interventions.

We offer this questionnaire for adaptation and use on other campuses. Among interesting questions which might be explored across the campuses are the following:

1. What are the actual and perceived responsibilities of teaching assistants regarding grading and how effective are they regarded as graders?

2. What is the relationship between course (and section) enrollments and ratings of teaching assistants?

3. In classes where students prefer more student talk, what do they want that talk to be about?

4. How do faculty who supervise teaching assistants prefer that time be allocated to activities? How accurately can they predict undergraduate responses to questions like those on the appended form? 


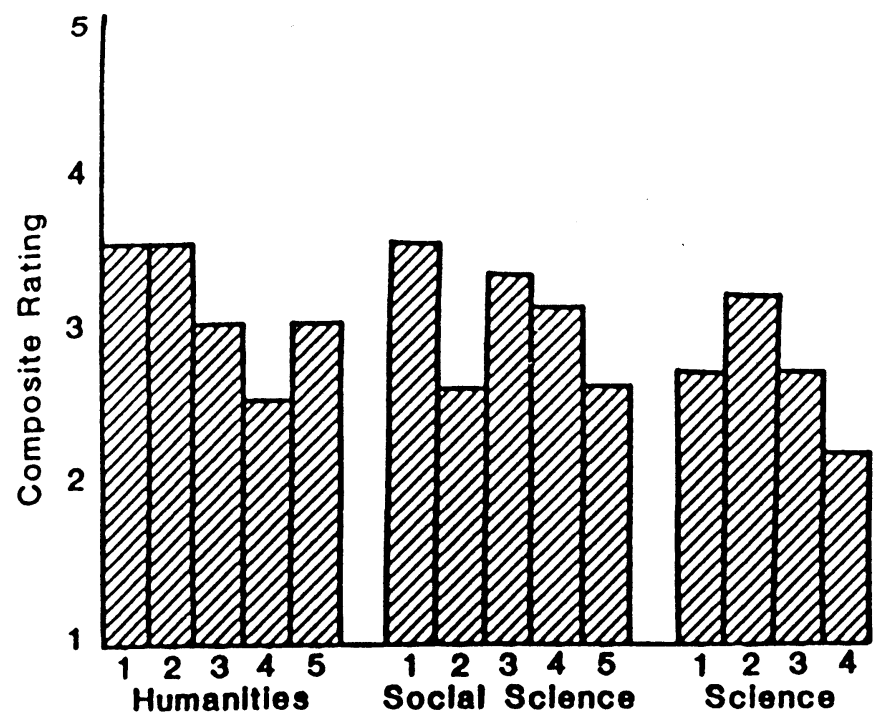

lgure 1. Average Ratings Across Teaching Asslstants for Fourteen Courses

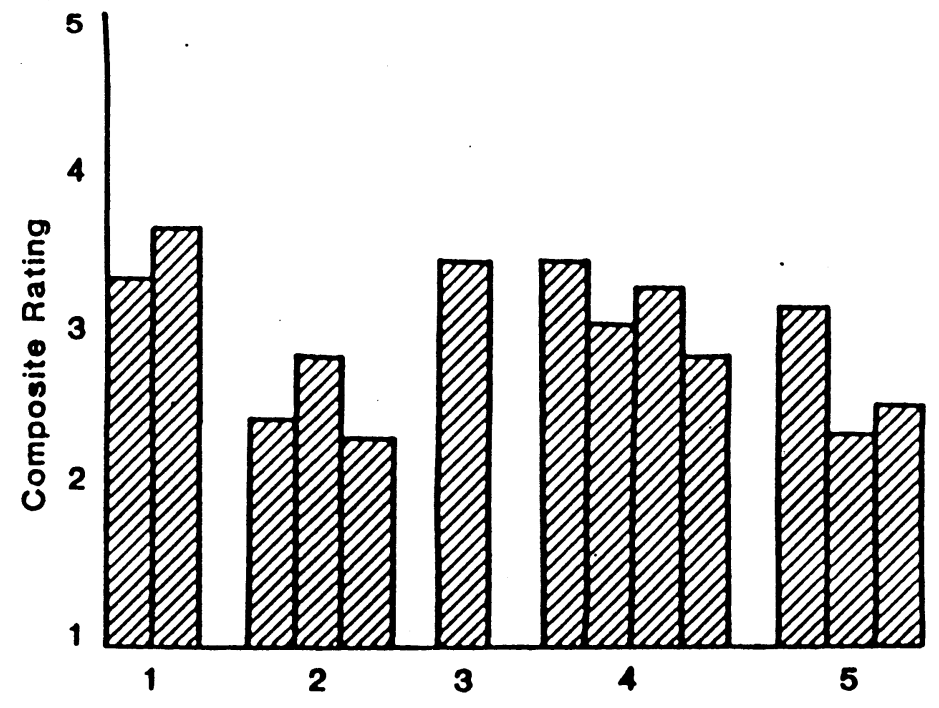

Flgure 2. Ratings of Teaching Assistants In Five Soclal Sclence Courses 


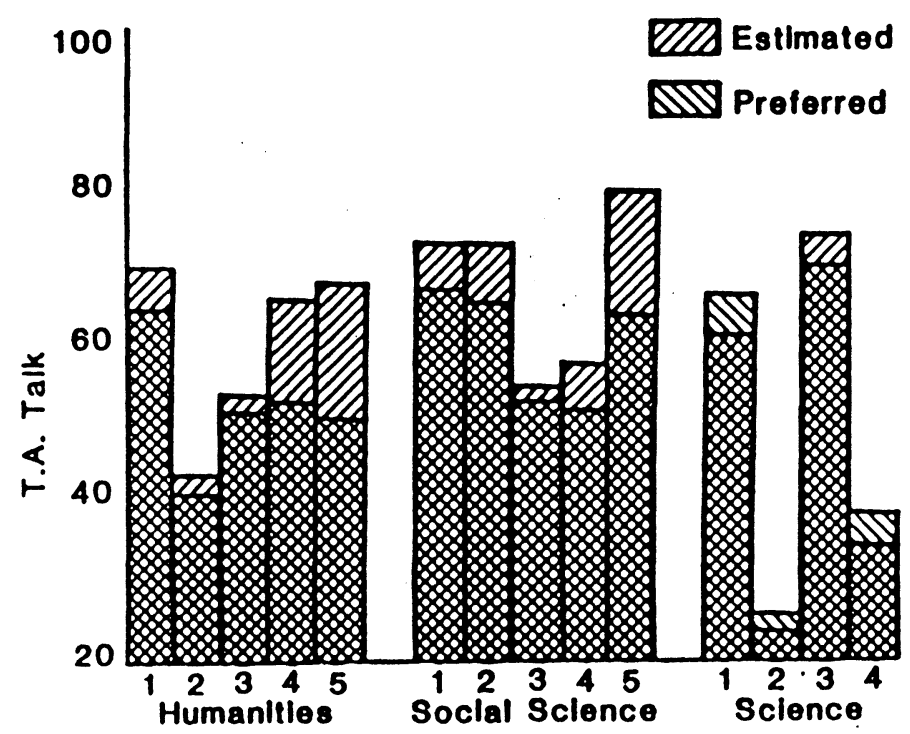

Figure 3. Proportion of Teaching Assistant Talk for Fourteen Courses

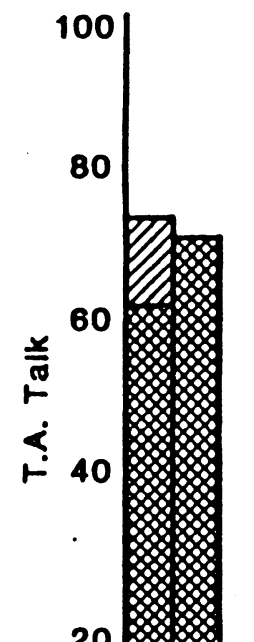

1

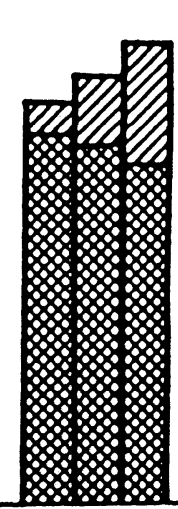

2

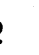

L

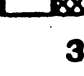

Eestimated

Preferred

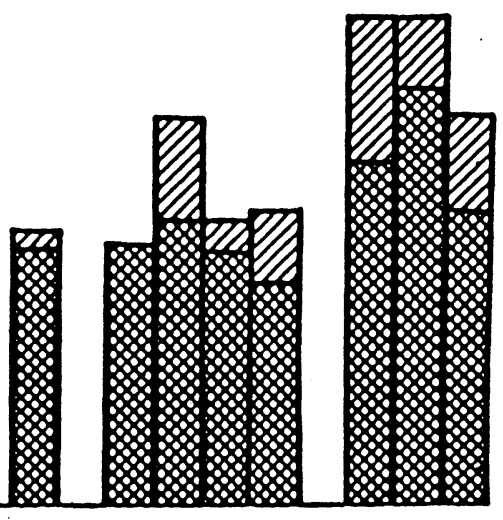

5

Figure 4. Proportion of Talk for Teaching Assistants In Five Soclal Science Courses 


\section{University Committee Survey}

The following questions are part of a survey for the University Senate Curriculum and Teaching Committee, and will not be published with the CTEC results. Questions refer to the work of Teaching Assistants in this course. Thank you for your help.

1. Your class

\begin{tabular}{ll} 
freshman \\
sophomore \\
junior \\
\hline & senior \\
& graduate
\end{tabular}

\section{Your school of enrollment:}

3. In this course were you assigned to: a discussion/quiz section conducted by a TA a lab conducted by a TA no TA for course (If you checked this response, it is not necessary to continue with the questionnaire.)

4. At what time were meetings with your TA scheduled? (This information is for use only in analyzing data. Individual TA's will be anonymous in the report.) day: hour: building \& room:

5. I attended these meetings: all of the time half of the time most of the time sometimes hardly ever

6. The TA was absent from scheduled meetings:

$\begin{array}{ll}\text { never } & \text { twice } \\ \text { once } & \text { more than twice }\end{array}$

7. The TA attended course lectures: all of the time most of the time half of the time 
Please estimate the percentage of time spent in various activities. For each of the next four questions, your response should total approximately $100 \%$.

Example: 40 talking by the TA 60 talking by students

8. About what percent of your meetings with the TA was devoted to: talking by the TA talking by students

9. About what percent of your meetings would you have preferred to be devoted to:

talking by the TA talking by students

10. About what percent of the meetings was devoted to each of the following:

Clarifying readings Clarifying lecture material Introducing new material Dealing with assignments Taking quiz or exam Grading and discussing quiz or exam Other

11. Now, please indicate what percent of section time should have been devoted to each activity in order to be most helpful to you.

Clarifying readings Clarifying lecture material Introducing new material Dealing with assignments Other

12. To what extent was the TA responsible for grading your work in the course?

1

not at all
Taking quiz or exam Grading and discussing quiz or exam 
13. The TA was well prepared for each meeting.
SA
A
$\mathbf{N}$
D
SD

14. The TA conveyed a thorough knowledge of the subject.
SA
A
$\mathbf{N}$
D
SD

15. The TA was readily available after class or during office hours for questions or consultation.
SA
A
$\mathbf{N}$
D
SD

16. The TA showed enthusiasm for the course.
SA
A
$\mathbf{N}$
D
SD

17. Based on your knowledge about other sections, grading standards seemed to be approximately uniform from section to section.
SA
A
$\mathbf{N}$
D
SD

18. Based on your knowledge about other sections, quality of instruction seemed to be approximately uniform from section to section.
SA
A
$\mathbf{N}$
D
SD

19. About how many TA's have you had so far at Northwestern?

1-3 4-6 7-9 10 or more

20. How competent have you found them to be in their own special fields?

all were competent one not sufficiently competent two or three not sufficiently competent several not sufficiently competent

21. Overall, my contact with the TA in this course:

1

detracted

from the course
2

3

4

enhanced

the course 
22. What were the strengths of your TA as a teacher in this course?

23. If there were problems for you in this course due to the $T A$ please mention them below. Give an example of a problem, if you can, but do not name the TA.

\section{References}

Change Magazine. How to succeed as a new teacher: $A$ handbook for teaching assistants. New Rochelle, NY: Change Magazine Press, 1978.

Friedrich, G., \& Powell, R. Workshop for graduate teaching assistants. Improving College and University Teaching, 1979,27, 171-173.

Levinson-Rose, J., \& Menges, R.J. Improving college teaching: A critical review of research. Review of Educational Research, 1981, 51, 403-434.

Staton-Spicer, A.Q., \& Nyquist, J.L. Improving the teaching effectiveness of graduate teaching assistants. Communication Education, 1979, 28, 199-205.

Williams, C.R. Are we preparing the TA for teaching? University of Kentucky News and Notes, 1977, 3(1), 1-7. 